\title{
EU and UK targets for healthy life expectancy - are they achievable?
}

\author{
Carol Jagger ${ }^{1, *}$
}

\begin{abstract}
In 2008, the EU Innovation Partnership on Active and Healthy Ageing (EIP-AHA) set a target of an increase of two healthy life years by 2020. More recently, in 2018, the UK Government set a target to "ensure people can enjoy at least 5 extra healthy, independent years of life by 2035, while narrowing the gap between the experience of the richest and poorest". This paper reviews the progress the EU member states have made towards meeting this target, and what the UK can learn from their experiences. I conclude that, although the EU target is likely to be reached, the gap in healthy life years between the member states has increased. Past trends in and projections of disability-free life expectancy in England suggest that it will be difficult to achieve an increase of five healthy and independent years of life by 2035 .
\end{abstract}

Keywords: health expectancy; life expectancy; healthy life years; social inequality; European Union

\section{Introduction}

In recent decades, the idea of focusing on the quality of remaining life - "adding life to years" - has become popular with the public and the academic community as a means of offsetting some of the challenges, both personally and societally, of population ageing. Health expectancies are population health indicators that combine information on health and mortality, and measure the remaining years spent in good health at a particular age. Health expectancies have also gained credence among governments as indicators of the outcomes of policies. In the early 2000s, the European Union developed healthy life years (HLY), a disability-free life expectancy, as the first pan-European health indicator. The health measure underlying HLY is the global activity limitation indicator, which is available

\footnotetext{
${ }^{1}$ Newcastle University, Population Health Sciences Institute, Newcastle upon Tyne, UK

${ }^{*}$ Correspondence to: Carol Jagger, carol.jagger@ncl.ac.uk
} 
annually in the EU Statistics of Income and Living Conditions (EU-SILC) survey. HLY was later chosen as the outcome for the European Innovation Partnership on Active and Healthy Ageing (EIP-AHA) target to "increase HLY by 2 years by 2020". More recently, the UK has declared as part of the Ageing Grand Challenge the intention to "increase by 5 years healthy and independent life by 2035 whilst narrowing the gap between the richest and the poorest". In this paper, I reflect on the likelihood that the UK will achieve this goal by looking first at the experiences of the EU, and then at past and forecasted trends in England. I conclude by discussing some approaches for achieving this target.

\section{EU trends}

Between 2010 and 2017, men's HLY at birth for the 28 member states of the EU (EU28) rose by 1.7 years, from 61.8 years to 63.5 years. Women's HLY at birth rose less, by 1.4 years, from 62.6 years to 64.0 years. Over this period, the gender gap in HLY declined slightly from 0.8 years to 0.5 years. Thus, if these trends continue, by the target date of 2020, HLY at birth will have increased by 2.4 years for men and by 2.0 years for women, the goal of an increase of two HLY will have been achieved, and the gender gap in HLY will be 0.4 years. Moreover, the gain in life expectancy at birth between 2010 and 2017 was 1.4 years for men and 0.7 years for women, which is evidence of a compression of disability for men and women. Whether the narrowing of the gender gap will continue is unknown. However if it does, it will likely to be due to the greater increase in LE in men than in women, which has been attributed to declines in cardiovascular and stroke mortality, as well as to the higher rate of smoking among women in the EU28 compared to in other countries (Leon et al. 2019; Sundberg et al. 2018).

Nevertheless, the picture is far from perfect. Inequalities in HLY between the EU28 member states have increased between 2010 and 2017, by 4.9 years for men's HLY and by 2.1 years for women's HLY. One factor that contributed to these increased inequalities is that the economic crisis was experienced differently by the member states. For example, the largest decreases in gross domestic product and the largest increases in unemployment were experienced by Latvia and Lithuania, the member states with some of the lowest life and healthy life expectancies in the EU (Stuckler et al. 2017). Increasing inequalities within the member states might have also contributed to inequalities in HLY. Nevertheless, increased inequalities were anticipated in a simulation of how these trends would play out (Jagger et al. 2013). For all member states to achieve two additional HLY by 2020 along with a reduction in the inequalities between the member states, an increase of 6.4 HLY would be required, which would lead to a $50 \%$ reduction in the gap. However reducing the gap by $50 \%$ alone would result in all but two member states, Malta and Sweden (which currently have some of the highest HLY levels in the EU28), gaining two additional HLY. 


\section{UK trends}

It is useful to look at the past trends in and current values of healthy life expectancy to assess whether the UK will be able to achieve its target. Through the Office for National Statistics (ONS), the UK has a long history of monitoring two health expectancies based on self-rated health (healthy life expectancy - HLE) and on limiting long-standing illness (disability-free life expectancy - DFLE). Between decennial censuses, these health expectancies do not include the population in residential care, but this lack of data has little effect on health expectancies at birth. Between 2009-11 and 2015-17, HLE at birth increased by 0.4 years for men and decreased by 0.2 years for women (Office for National Statistics 2018). However, over this period, gains in life expectancy at birth were greater, at 0.8 years for men and at 0.6 years for women. For both men and women, years lived in "not good" health increased in relative and in absolute terms, with a consequent expansion of morbidity. Over the 20-year period between 1991 and 2011, HLE at age 65 increased by 3.8 years for men and by 3.1 years for women (Jagger et al. 2016). As these increases were significantly smaller than the increases in life expectancy (4.5 years for men and 3.6 years for women), there was again an increase in years spent with ill health, and, therefore, an expansion of morbidity. DFLE at age 65 for men increased again, but by only 2.6 years, which was smaller than the increase in HLE. However, since DFLE at age 65 for women increased by only 0.5 years, the majority of the 3.6 years in life expectancy women gained were years spent with disability. The number of years spent living independently at age 65 followed a similar pattern, increasing by 1.7 years for men, but by only 0.2 years for women (Kingston et al. 2017).

Although there is a body of work on gender disparities in health expectancies, little is known about gender disparities in trends in health expectancies. While there is evidence that differential health reporting between men and women may contribute to differences in health expectancy (di Lego et al. 2020), the greater prevalence of chronic conditions among women (disabling conditions such as arthritis) than among men (more fatal conditions such as cardiovascular disease) appears to play a part as well. However, though differential reporting may affect the gender differences in health expectancies, it is unlikely to result in different trends. The decline in fatalities caused by chronic conditions among men may have led to the gap between DFLE and LE being narrowed more among men than among women.

Looking at the potential for narrowing the HLE gap between rich and poor, it is clear that inequalities in HLE between socio-economic groups are large in the UK, at around 19 years for men and women at birth, or double the inequalities in life expectancy at birth (Office for National Statistics 2019). There is evidence that inequalities increased slightly between 2012-14 and 2015-17. Large inequalities in multimorbidity have also been found (Chan et al. 2019). These findings suggest that when it comes to reducing inequalities in HLE in the UK, there is still a long way to go. 
Simulation models that forecast the health of future populations have been developed, but few of these models incorporate forecasts of health expectancy (Jagger and Kingston 2020). The most comprehensive of these approaches is the Population Ageing and Care Simulation (PACSim) model, as it overcomes a number of the limitations of other models. Specifically, PACSim: (a) brings together the three national or nationally representative longitudinal studies of ageing covering England for the base population; (b) includes the real health and lifestyle profiles of people aged 35 years and over who will age into the older population aged 65 and over during the subsequent 20 years; and (c) includes a wide range of socio-demographic characteristics, health behaviours, and 12 diseases and geriatric conditions that allow for an estimate of multimorbidity. PACSim forecasts that between 2015 and 2035, years spent independent from age 65 will increase by 4.2 years for men and 0.9 years for women (Kingston et al. 2018). Since for men, life expectancy at age 65 will increase less than the years spent independent, there will be a compression of dependency for men. For women, on the other hand, there will be an increase in dependency - although the level of dependency among women will be relatively low, requiring care less frequently than daily. PACSim also forecasts considerable increases in the prevalence of and the years spent with multimorbidity (Kingston et al. 2018). The reasons for this trend are two-fold. First, the numbers of very old people, among whom multimorbidity is common, are rising. Second, people entering the older population in subsequent years have a greater likelihood of already having one disease.

\section{Conclusions}

The evidence from past trends and forecasts suggest that it will not be easy for the UK to achieve the target of increasing the number of healthy, independent years Britons can enjoy by five years, while narrowing the gap between the richest and poorest population groups. Lessons learned from the EU's experiences with HLY trends indicate that there is a need to focus on narrowing the gap, as national strategies designed to increase HLE are likely to result in the greatest increases occurring in the most advantaged areas. Nevertheless, narrowing the gap will be particularly challenging given the size of the current gap, and the direction of change (currently increasing). Gaining an understanding of the barriers to the uptake of healthy behaviours (healthy diet, physical activity, smoking cessation, reducing alcohol consumption) in the most disadvantaged communities, as well as making investments in communities, raising employment levels, and taking into account the wider social determinants of health, are all required (All Party Parliamentary Group for Longevity 2020).

In considering which strategies might improve HLE, there are three points worth noting. First, the increases in years spent with multimorbidity indicate that there is a need for a greater focus on prevention in early and mid-adulthood, as well as on delaying the disabling consequences of chronic conditions. Second, most of the 
remaining years of life after age 65 are spent living independently. Given that ageing is malleable, interventions and strategies aimed at delaying decline will be most beneficial in achieving gains in years of healthy, independent life (Gore et al. 2018). However, finding solutions will require gaining an understanding of the barriers that more disadvantaged adults face in adopting healthy lifestyles, as well as recognising that implementing these solutions may require greater investment in, for example, jobs, housing, leisure facilities, and neighbourhood improvements.

Third, and perhaps most important, it is crucial to monitor both HLE and LE together, since interventions may increase HLE, but if they increase LE by the same amount or more, there will be an overall increase in unhealthy years. A good illustration of this dynamic is the differing effects of smoking and obesity on DFLE. Evidence from cross-sectional studies suggests that, of the three lifestyle factors assessed - smoking, obesity, and alcohol consumption - obesity is most strongly associated with spending more years of life with disability, with obese individuals living on average more years with disability (5.9 years) than smokers (3.8 years) and drinkers (3.1 years) (Klijs et al. 2011). In contrast, there is evidence that smoking has the strongest effect on life expectancy, with life expectancy at age 55 differing by 4.0 years based on smoking, 3.0 years based on alcohol consumption, and 1.4 years based on BMI. Longitudinal observational studies have generated similar findings (Majer et al. 2011).

In conclusion, reaching the UK target of an increase of five healthy and independent years of life by 2035, while narrowing the socio-economic gaps in HLE and DFLE, may be attainable for men, but will not be easy for women. It appears likely that the overall European target will be achieved by 2020 , but will be accompanied by increased inequalities between member states, many of which will not see the same gains, or any increase at all. Nevertheless, countries must aspire to reach such targets if we are to achieve the longer term goals of enabling healthy ageing for all, and of gaining some control over the rising demands for health and social care worldwide.

\section{References}

All Party Parliamentary Group for Longevity 2020. The Health of the Nation - a strategy for healthier longer lives. London: Longevity UK.

Chan, M. S., A. van den Hout, M. Pujades-Rodriguez, M. M. Jones, F. E. Matthews, C. Jagger, R. Raine and M. Bajekal 2019. Socio-economic inequalities in life expectancy of older adults with and without multimorbidity: a record linkage study of 1.1 million people in England. International Journal of Epidemiology 48(4): 1340-1351. https: //doi.org/10.1093/ije/dyz052.

di Lego, V., P. Di Giulio and M. Luy 2020. Gender differences in healthy and unhealthy life expectancy. In International Handbook of Health Expectancies, eds C. Jagger, E. C. Crimmins, Y. Saito, R. Tiene de Carvalho Yokota, H. van Oyen and J.-M. Robine. Springer. 
Gore, P. G., A. Kingston, G. R. Johnson, T. B. L. Kirkwood and C. Jagger 2018. New horizons in the compression of functional decline. Age and Ageing 47(6): 764-768. https://doi.org/10.1093/ageing/afy145.

Jagger, C. and A. Kingston 2020. Forecasting health expectancy - what the future might hold. In International Handbook of Health Expectancies, eds C. Jagger, E.C. Crimmins, Y. Saito, R. Tiene de Carvalho Yokota, H. van Oyen and J.-M. Robine. Springer.

Jagger, C., F. E. Matthews, P. Wohland, T. Fouweather, B. C. Stephan, L. Robinson, A. Arthur and C. Brayne 2016. A comparison of health expectancies over two decades in England: results of the Cognitive Function and Ageing Study I and II. Lancet 387(10020): 779-786. https://doi.org/10.1016/s0140-6736(15)00947-2.

Jagger, C., M. McKee, K. Christensen, K. Lagiewka, W. Nusselder, H. Van Oyen, E. Cambois, B. Jeune and J.-M. Robine 2013. Mind the gap-reaching the European target of a 2-year increase in healthy life years in the next decade. European Journal of Public Health 23(5): 829-833. https://doi.org/10.1093/eurpub/ckt030.

Kingston, A., A. Comas-Herrera and C. Jagger, for the Modem Project 2018. Forecasting the care needs of the older population in England over the next 20 years: estimates from the Population Ageing and Care Simulation (PACSim) modelling study. Lancet Public Health 3(9): E447-E455. https://doi.org/10.1016/s2468-2667(18)30118-X.

Kingston, A., P. Wohland, R. Wittenberg, L. Robinson, C. Brayne, F. E. Matthews and C. Jagger 2017. Is late-life dependency increasing or not? A comparison of the Cognitive Function and Ageing Studies (CFAS). Lancet 390(10103): 1676-1684. https://doi.org/10. 1016/s0140-6736(17)31575-1.

Kingston, A., L. Robinson, H. Booth, M. Knapp and C. Jagger 2018. Projections of multimorbidity in the older population in England to 2035: estimates from the Population Ageing and Care Simulation (PACSim) model. Age and Ageing 47(3): 374-380. https://doi.org/10.1093/ageing/afx201.

Klijs, B., J. P. Mackenbach and A. E. Kunst 2011. Obesity, smoking, alcohol consumption and years lived with disability: a Sullivan life table approach. BMC Public Health 11(1): 378. https://doi.org/10.1186/1471-2458-11-378.

Leon, D. A., D. A. Jdanov and V. M. Shkolnikov 2019. Trends in life expectancy and agespecific mortality in England and Wales, 1970-2016, in comparison with a set of 22 high-income countries: an analysis of vital statistics data. The Lancet Public Health 4(11): e575-e582. https://doi.org/10.1016/S2468-2667(19)30177-X.

Majer, I. M., W. J. Nusselder, J. P. Mackenbach and A. E. Kunst 2011. Life expectancy and life expectancy with disability of normal weight, overweight, and obese smokers and nonsmokers in Europe. Obesity (Silver Spring) 19(7): 1451-1459. https://doi.org/10.1038/ oby.2011.46.

Office for National Statistics 2018. Health state life expectancies, UK: 2015 to 2017.

Office for National Statistics 2019. Health state life expectancies by national deprivation deciles, England and Wales: 2015 to 2017.

Stuckler, D., A. Reeves, R. Loopstra, M. Karanikolos and M. McKee 2017. Austerity and health: the impact in the UK and Europe. European Journal of Public Health 27 (suppl_4): 18-21. https://doi.org/10.1093/eurpub/ckx167. 
Sundberg, L., N. Agahi, J. Fritzell and S. Fors 2018. Why is the gender gap in life expectancy decreasing? The impact of age- and cause-specific mortality in Sweden 1997-2014. International Journal of Public Health 63(6): 673-681. https://doi.org/10.1007/s00038018-1097-3.

Open Access This article is published under the terms of the Creative Commons Attribution 4.0 International License (https://creativecommons.org/licenses/by/4.0/) that allows the sharing, use and adaptation in any medium, provided that the user gives appropriate credit, provides a link to the license, and indicates if changes were made. 